\title{
BestMasters
}


Springer awards „BestMasters“ to the best master's theses which have been completed at renowned universities in Germany, Austria, and Switzerland.

The studies received highest marks and were recommended for publication by supervisors. They address current issues from various fields of research in natural sciences, psychology, technology, and economics.

The series addresses practitioners as well as scientists and, in particular, offers guidance for early stage researchers. 
Daniel Halwidl

\section{Development of an \\ Effusive Molecular \\ Beam Apparatus}

照 Springer Spektrum 
Daniel Halwidl

Wien, Österreich

BestMasters

ISBN 978-3-658-13535-5

ISBN 978-3-658-13536-2 (eBook)

DOI 10.1007/978-3-658-13536-2

Library of Congress Control Number: 2016935968

Springer Spektrum

(C) Springer Fachmedien Wiesbaden 2016

This work is subject to copyright. All rights are reserved by the Publisher, whether the whole or part of the material is concerned, specifically the rights of translation, reprinting, reuse of illustrations, recitation, broadcasting, reproduction on microfilms or in any other physical way, and transmission or information storage and retrieval, electronic adaptation, computer software, or by similar or dissimilar methodology now known or hereafter developed.

The use of general descriptive names, registered names, trademarks, service marks, etc. in this publication does not imply, even in the absence of a specific statement, that such names are exempt from the relevant protective laws and regulations and therefore free for general use.

The publisher, the authors and the editors are safe to assume that the advice and information in this book are believed to be true and accurate at the date of publication. Neither the publisher nor the authors or the editors give a warranty, express or implied, with respect to the material contained herein or for any errors or omissions that may have been made.

Printed on acid-free paper

Springer Spektrum imprint is published by Springer Nature

The registered company is Springer Fachmedien Wiesbaden GmbH 


\section{Acknowledgements}

I would like to express my gratitude and appreciation to my supervisors Prof. Ulrike Diebold and Jiri Pavelec, who supported me during my diploma thesis. I want to especially thank Jiri Pavelec for the technical drawings and encouraging me in my work. I also feel grateful to Prof. Michael Schmid, who was always available for fruitful discussions.

I want to thank Herbert Schmidt and Rainer Gärtner, who showed great skills and patience when it came to the production of the many parts the Molecular Beam consists of.

Many thanks I want to adress to Jan Hulva, Manfred Bickel, Florian Brunbauer and Jakub Piastek for their support in the laboratory.

Finally, I want to thank my family for supporting me during my study.

Daniel Halwidl 


\section{Abstract}

This thesis describes the development of an effusive molecular beam apparatus, which allows the dosing of gases, liquids and solids. The apparatus was designed to adsorb precise and reproducible doses to a defined area on metal oxide samples, which is required in Thermal Programmed Desorption and other surface chemistry experiments in the "Machine for Reactivity Studies". The theoretical profile of the molecular beam has a core diameter of $3.5 \mathrm{~mm}$ and a standard core pressure of $4 \times 10^{-8}$ mbar, while the background pressure of the beam is 4 orders of magnitude lower. The design and the construction of the apparatus is described. The calculated beam profile was experimentally confirmed and core pressures between $1.7 \times 10^{-8}$ mbar and $2.9 \times 10^{-6}$ mbar were measured. 


\section{Kurzfassung}

Diese Diplomarbeit beschreibt die Entwicklung einer effusiven Molekularstrahlapparatur für die Adsorption von Gasen, Flüssigkeiten und Feststoffen auf Metalloxidproben in der "Machine for Reactivity Studies". Die Adsorption einer präzisen, reproduzierbaren Dosis auf einem wohldefinierten Bereich der Probenoberfläche ist für Thermische Desorptionsspektroskopie und andere Methoden der Oberflächenchemie notwendig. Das berechnete Profil des Molekularstrahls weist einen Kern mit Durchmesser $3.5 \mathrm{~mm}$ und einen Standarddruck von $4 \times 10^{-8} \mathrm{mbar}$ auf, während der Hintergrunddruck des Molekularstrahls um 4 Größenordnungen kleiner ist. Der Entwurf und die Konstruktion des Apparats sind beschrieben. Das berechnete Profil wurde experimentell bestätigt und ein Druck von $1.7 \times 10^{-8} \mathrm{mbar}$ bis $2.9 \times 10^{-6}$ mbar im Kern des Molekularstrahls gemessen. 


\section{Contents}

Acknowledgements $\quad$ V

$\begin{array}{lll}\text { Abstract } & \text { VII }\end{array}$

Kurzfassung $\quad$ IX

$\begin{array}{ll}\text { List of Figures } & \text { XIII }\end{array}$

List of Tables $\quad$ XVII

1 Introduction 1

1.1 Molecular Beams . . . . . . . . . . . . . . . . . 2

1.2 Temperature Programmed Desorption . . . . . . . . . 3

2 Flow of Gases 5

2.1 Flow Regimes . . . . . . . . . . . . . . . . . . 5

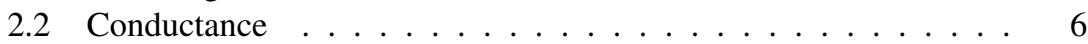

2.2.1 Molecular flow . . . . . . . . . . . . . . . . 7

2.2 .2 Continuum flow . . . . . . . . . . . . . . 11

2.2.3 Transition flow and conductance over the whole pressure range ..................... 15

3 Effusive Molecular Beam Sources $\quad 19$

3.1 Thin-walled Orifice . . . . . . . . . . . . . . . . . . . . . . . . . 19

3.2 Single Tube . . . . . . . . . . . . . . . . . . . 21

3.3 Capillary Array . . . . . . . . . . . . . 22

4 Molecular Beam $\quad 25$

4.1 Requirements . . . . . . . . . . . . . . . . . . . . . 25

4.2 Concept . . . . . . . . . . . . . . . . . . . 27

4.3 Theory......................... 30 
4.3.1 Core and Penumbra . . . . . . . . . . . . . . . 30

4.3 .2 Equivalent pressure . . . . . . . . . . . . . . . 34

4.3.3 Molecular Beam intensities and doses . . . . . . . . . . 34

4.3 .4 Geometry . . . . . . . . . . . . . . . . . . 37

4.3.5 Molecular Beam dimensions . . . . . . . . . . . . . . . 42

4.3.6 Pressures in the pumping stages and the chamber . . . . . 43

4.3.7 Effusing gas from the pumping stages . . . . . . . . . 46

4.3.8 Molecular Beam properties . . . . . . . . . . . . . . . . 47

4.3 .9 Capillary pressure . . . . . . . . . . . . . . . 50

4.4 Construction . . . . . . . . . . . . . . . . . 53

4.4.1 Overview ................... 53

4.4.2 Molecular Beam Core Part . . . . . . . . . . . . . . 54

4.4 .3 Shutter Motor . . . . . . . . . . . . . . . . . . . . 59

4.4 .4 Pumping stages . . . . . . . . . . . . . . . . 62

4.4 .5 Reservoir . . . . . . . . . . . . . . . . . 67

4.4 .6 Pumping speed . . . . . . . . . . . . . . 68

4.4.7 Aperture and Shutter conductances . . . . . . . . . 72

5 Results $\quad 75$

5.1 Test Setup . . . . . . . . . . . . . . . . . . . . 75

5.1.1 Argon correction factor . . . . . . . . . . . . . . 77

5.2 Molecular Beam Profile . . . . . . . . . . . . . . . . . . . . 79

5.2.1 Molecular Beam line profile . . . . . . . . . . . . 79

5.2 .2 Molecular Beam 2D profile . . . . . . . . . . . . 84

5.2.3 Pumping Stage 1 core and penumbra . . . . . . . . . . . 84

5.2.4 Molecular Beam Background . . . . . . . . . . . . 85

5.3 Shutter . . . . . . . . . . . . . . . . 86

6 Summary and Outlook $\quad 89$

A Gas Properties $\quad 91$

A.1 Maxwell-Boltzmann Distribution . . . . . . . . . . . . . . . . 91

B Conductance $\quad 93$

B.1 Molecular Flow in an Annular Tube . . . . . . . . . . . . . . . 93

B.2 Orifice in Transition Flow . . . . . . . . . . . . . . . . . . . . . 99

$\begin{array}{ll}\text { C Pirani Gauge Argon Correction Factor } & 101\end{array}$

$\begin{array}{ll}\text { References } & 103\end{array}$ 


\section{List of Figures}

2.1 Transmission probability for a tube in molecular flow . . . . . . 9

2.2 Transmission probability for an annular tube in molecular flow . . 10

2.3 Flow function $\psi$ in continuum flow . . . . . . . . . . . . . . 14

2.4 Interpolation of experimental values for the orifice conductance . . 16

2.5 Conductance function $f$ and correction factor $Z$ for the conductance of a tube . . . . . . . . . . . . . . 18

3.1 Angular dependence of the intensity per unit area from a thinwalled orifice . . . . . . . . . . . . . . . 20

3.2 Angular intensity distribution of a tube . . . . . . . . . . 22

3.3 Intensity distribution of a capillary array on a planar sample . . . . 23

4.1 Ideal intensity distribution of the MB on the sample . . . . . . 25

4.2 Schematic of the working principle of the MB . . . . . . . . . 27

4.3 Reservoir supply and pumping schematic of the MB . . . . . . . . 29

4.4 Geometry of source, aperture and plane with core and penumbra . 31

4.5 Intensity in the penumbra . . . . . . . . . . . . . 33

4.6 The ratio of approximated to integrated relative penumbra dose . . 34

4.7 Denotation of doses in the different areas of the MB on the sample 35

4.8 Geometry schematic of the MB . . . . . . . . . . . . . . . . 39

4.9 Contour plot of the MB core pressure in dependence of the Orifice and Aperture 2 distance . . . . . . . . . . . . . . . . . . . 42

4.10 Intercepted molecular beam areas at the PS2 side of Aperture 2 . . 45

4.11 Capillary pressure as a function of the Reservoir pressure for a pumping orifice diameter of $d_{\mathrm{PO}}=800 \mu \mathrm{m} \ldots \ldots$. . . . . . 51

4.12 Capillary pressure as a function of the Reservoir pressure for a pumping orifice diameter of $d_{\mathrm{PO}}=150 \mu \mathrm{m} \ldots \ldots . \ldots 51$

4.13 Average time for a water molecule to leave a capillary according to a random walk model . . . . . . . . . . . . . . . 53

4.14 3D model of the Molecular Beam . . . . . . . . . . . . 55 
4.15 MB Core Part . . . . . . . . . . . . . . . . . . . . 56

4.16 Orifice Inset without and with laser-welded Orifice . . . . . . . 57

4.17 SEM images of the Orifices . . . . . . . . . . . . . . . . . 57

4.18 Aperture 1 and Aperture $2 \ldots \ldots \ldots$. . . . . . . . . 58

4.19 Cross section of the MB Core Part with mounted Orifice Inset, Aperture 1 and Aperture $2 \ldots \ldots \ldots$

4.20 Shutter Assembly . . . . . . . . . . . . . . . . . . . . . . . 59

4.21 Shutter Assembly mounted on the MB Core Part and Aperture 2

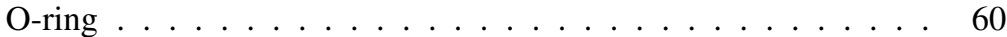

4.22 Coil cores and Motor Lever of the Shutter Motor . . . . . . . . 61

4.23 Shutter Motor . . . . . . . . . . . . . . . . . . . . . . 61

4.24 PS2 Shell and Rear Ring of the Parallel Shift Cage . . . . . . . 62

4.25 PS1 . . . . . . . . . . . . . . . . . . . . 64
(a) PS1 Front Assembly.
(b) PS1 Front Assembly inserted into the Parallel Shift Cage.

4.26 Position adjustment and Pushing Ring . . . . . . . . . . . . 65

(a) Position adjustment of the MB

(b) Pushing Ring at the back of the PS1 Back Tube

4.27 PS1 Rear Assembly . . . . . . . . . . . . . . . . . . . . . . 65

4.28 MB Tee and PS1 Feedthrough Reducer . . . . . . . . . . . . . 66

4.29 D-sub connection and D-sub feedthrough . . . . . . . . . . . 67

(a) D-sub connection and CF 40 6-way cross

(b) Layout of the atmosphere side of the D-sub feedthrough

4.30 Reservoir Tube . . . . . . . . . . . . . . . . . . . . . 68

4.31 View inside the PS1 Back Tube towards the MB Core Part . . . . 69

4.32 Reservoir connection at the backside of the MB Cross . . . . . . . 69

4.33 Cross section of the MB Core Part with Aperture details . . . . . 71

5.1 Schematic of the test setup . . . . . . . . . . . . . . . 77

5.2 Photograph of the test setup . . . . . . . . . . . . . 78

(a) Overview

(b) Equipment connected to the Reservoir

5.3 Line profile of the MB for $p_{\mathrm{r}}=4.1 \times 10^{-1} \mathrm{mbar} \ldots \ldots$. . . . 80

5.4 Detailed line profile of the rising edge of the MB . . . . . . 81

5.5 Line profile of the MB for $p_{\text {Pir }}=10$ mbar . . . . . . . . 82

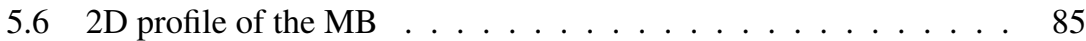

5.7 Line profile of the PS1 core and penumbra . . . . . . . . . 86

5.8 Line profile of the MB Background . . . . . . . . . . . . . 87 
B.1 Correction factor, $K_{0}$, for Knudsen's formula for the conductance of an annular tube . . . . . . . . . . . . . . . . . . 94

B.2 Comparison of the various formulas for the conductance of annular

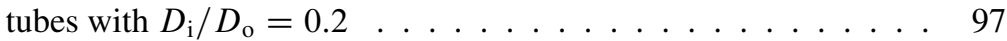

B.3 Comparison of the various formulas for the conductance of annular tubes with $D_{\mathrm{i}} / D_{\mathrm{o}}=0.8 \ldots \ldots \ldots$

C.1 Pressure reading of the spinning rotor gauge as a function of the Pirani gauge reading . . . . . . . . . . . . . 102 


\section{List of Tables}

2.1 Molecular orifice conductance per area for gases . . . . . . . . . 8

2.2 Isentropic exponent, critical pressure ratio, and maximum value of the flow function for various gas species . . . . . . . . 12

4.1 Notation used in the geometry schematic (Fig. 4.8) and the calcu-

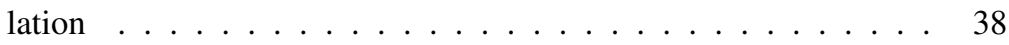

4.2 Dimensions of the MB . . . . . . . . . . . . . . . 44

4.3 Relative doses of the MB and the relative MB background pressure 48

4.4 MB properties for the standard Reservoir pressure . . . . . . . . . 49

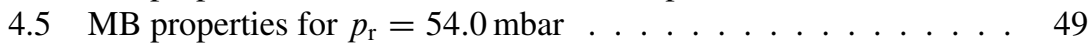

4.6 Components of the approximated tubing from the volume behind Aperture 1 to the PS1 TMP . . . . . . . . . . . . 70

4.7 Components of the approximated tubing from the volume behind Aperture 2 to the PS2 TMP . . . . . . . . . . . . . . 72

4.8 Components of the model for the Aperture 1 conductance . . . . . 72

4.9 Components of the model for the Aperture 2 conductance . . . . . 73

5.1 Theoretical and experimental MB properties for standard Reservoir pressure . . . . . . . . . . . . . . 81

5.2 Theoretical and experimental MB properties for a Reservoir pressure of $p_{\text {Pir }}=10$ mbar $\ldots \ldots \ldots \ldots . \ldots \ldots 4$

5.3 Pressure in PS2 in dependence of the set pressure in PS1 and the

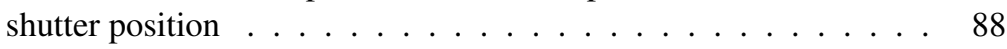

A.1 Standard atomic weight, viscosity and average particle velocity of

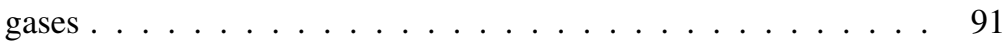

B.1 Correction factor, $K_{0}$, for Knudsen's formula for the conductance of an annular tube . . . . . . . . . . . . . . . . . 94

B.2 Transmission probability values for an annular tube, read off [13, Fig. 4.39] . . . . . . . . . . . . . . . 95 
B.3 Experimental values for the orifice conductance, read off [12, Fig.2] 99

C.1 Measured SRG and Pirani gauge pressures for Ar . . . . . . . . 101 